\title{
TRABALHO DOCENTE E PROLETARIZAÇÃO
}

\author{
Ana Elizabeth Santos Alves \\ Universidade Estadual do Sudoeste da Bahia - UESB \\ ana_alves@hotmail.com
}

\section{RESUMO:}

Este artigo tem como objetivo central refletir acerca das razões que levam os docentes a serem rotulados de proletários na literatura sobre o tema. Para tanto, revisitamos brevemente algumas teses sobre proletarização e analisamos a posição dos docentes na divisão social do trabalho, retomando algumas discussões sobre classe. Os debates situamse em torno de interpretações que, de um lado, explicam o trabalho docente como caracteristicamente capitalista ou como não capitalista e, de outro, descartam a polarização e buscam esclarecer o trabalho docente como síntese de relações sociais, considerando os professores como sujeitos participativos que se aliam a outros trabalhadores como prática de resistência.

Palavras-chave: Trabalho docente. Proletarização.

\section{TEACHING EXPERIENCE AND PROLETARIANIZATION}

\begin{abstract}
:
This article was aimed at reflecting on the reasons for teachers to be labeled workers literature on the subject, to this end, we revisit briefly some theories of proletarianization and analyze the position of teachers in the social division of labor. The debates are located around interpretations on the one hand, explain the teachers' work as distinctively as capitalist or non-capitalist and other explanations are ruled out bias and attempt to clarify the teacher's work as a synthesis of social relations, considering teachers as subjects participatory ally to other workers as a practice of resistance.

Key words: Teachers' work. Proletarianization
\end{abstract}

Causaram impactos no mundo do trabalho o ingresso de inovações tecnológicas e organizacionais no processo produtivo, final do século XX no Brasil, e a introdução de conceitos como globalização, flexibilização e competências. O reflexo dessas mudanças produziu um processo de precarização estrutural do trabalho, com aumento do desemprego, aumento do trabalho temporário e a instabilidade, parcialidade e terceirização do trabalho. A generalização desse processo culminou na desqualificação da força de trabalho, na intensificação da jornada e do ritmo de trabalho, na adoção do processo produtivo flexível e todo o seu corolário discursivo de multifuncionalidade, por necessidade de desenvolver diferentes tarefas e aumentar a qualificação, como estratégias para usufruir da capacidade intelectual e manual do trabalhador e proporcionar maior valorização do capital. Essas questões são duplamente vivenciadas na educação: pela adoção de novos padrões de remuneração e contratação dos professores conforme o padrão flexível e, mais ainda, pela materialização de propostas de reformas curriculares para as escolas, de políticas de formação de professores, afetando, sobremaneira, o trabalho docente. 
Há, naturalmente, muito a ser discutido em relação às consequências do processo de reestruturação produtiva na educação. Entretanto, o que nos interessa refletir neste texto é o trabalho do professor, especificamente os estudos que analisam essa categoria à luz das relações sociais de produção e discutem a tese da proletarização. Por exemplo, um dos princípios das propostas elaboradas pelo Unicef, para reformulação das políticas de formação de professor, recomenda a introdução de mecanismos de controle do trabalho por meio da redução de custos: "seja pelo emprego de professores qualificados com baixos salários, seja pela participação daqueles com pouca qualificação cuja mão-de-obra é barata, o que seria compensado por treinamentos em serviços" (SHIROMA, 2003, p.64). Uma reforma que tem como objetivo central diminuir o controle que os professores têm sobre o seu trabalho, tornando-os proletários e desintelectualizados, demonstra que esses profissionais estão sujeitos à constante ameaça de desqualificação e precarização. Parecenos, assim, que o trabalhador da educação "carrega as marcas da condição proletária". (BRAVERMAN, 1980, p.344).

Se as transformações que ocorrem/ocorreram no mundo do trabalho afetam o trabalho do professor, será que podemos considerar que esse profissional está sendo proletarizado, isto é, está perdendo as suas qualificações e, por isso, se assemelhando à classe operária, fabril? Essas discussões não são novas. Vários autores (APPLE e TEITELBAUN, 1991; PUCCI et al., 1991; OZGA e LAWN, 1991; JÁEN, 1991; ENGUITA, 1991; COSTA,1995; FERREIRA, 2006; LÜDKE e BOING, 2007) já se debruçaram sobre as semelhanças entre o trabalho de um professor, de um profissional e de um proletário. Há um vasto e polêmico debate acerca deste assunto. As principais dúvidas que emergem a respeito desse tema, para nós, referem-se à compreensão do que é ser proletário e às razões que levam o professor a ser assim rotulado. Este artigo, portanto, tem como objetivo central refletir sobre essas questões e, para tanto, analisa a posição do professor na divisão social do trabalho, retoma algumas discussões sobre classe e, em seguida, revisita brevemente algumas teses da proletarização.

Em que pesem a importância dos estudos elaborados pelos autores sobre o trabalho docente e o quanto as polêmicas alimentam as discussões sobre o tema, trazendo explicações a respeito da proletarização, pensamos contribuir para o debate centrando nossa análise nas explicações a respeito de proletário, proletarização, na origem do termo proletarização para, em seguida, situar a categoria docente e, assim, tornar mais fácil a compreensão dos motivos que levam o professor a ser chamado de proletário na sua essência. Neste sentido, parece-nos fundamental começar pelos esclarecimentos dados por Marx e Engels acerca da produção da vida humana.

\section{O que é proletarização}

Marx e Engels (2007, p. 32-34) explicam que o primeiro ato histórico da existência humana é a produção dos meios que possibilitam a satisfação das necessidades básicas da vida material, como comer, beber, vestir-se, e a produção da própria vida, que tem de ser cumprida diariamente, até hoje, para manter homens e mulheres vivos. Satisfeitas essas necessidades, as ações seguem no intuito de realizar novas necessidades, ao tempo em que homens e mulheres se relacionam mutuamente, procriando, formando famílias, constituindo-se na gênese da primeira relação social. À medida que surgem outras necessidades e a população cresce, são geradas novas relações sociais. A produção da vida humana, na procriação, no trabalho, forma-se por meio de uma relação de duplo caráter: natural de um lado e social, de outro. Independente do modo de produção, a relação social entre os homens, compreendida como a cooperação dos indivíduos, sob quaisquer 
condições históricas, está sempre ligada a um determinado modo de cooperação e a uma dada evolução das forças produtivas. Assim, "a 'história da humanidade' deve ser estudada e elaborada sempre em conexão com a história da indústria e das trocas".

Outra dimensão, ressaltada por Marx e Engels, refere-se ao fato de homens e mulheres também terem uma "consciência", que se manifesta pela ação da linguagem nas relações sociais. A consciência é, a um só tempo, a noção que o indivíduo tem do mundo que o cerca e do vínculo que ele tem com outras pessoas e com a natureza e de que é um ser social, que vive, decisivamente, em uma sociedade.

$\mathrm{O}$ instinto (instinto consciente) de sobrevivência, provocado pelo aumento das necessidades e da população, impulsiona o aumento da produtividade e o desenvolvimento da divisão do trabalho, que, sem dúvida, se torna partilha quando há uma divisão entre trabalho espiritual e material. Esta divisão pode ser exemplificada pelo trabalho desenvolvido por ideólogos e sacerdotes (construção da teoria, da teologia, da filosofia, da moral; o trabalho intelectual dos pensadores, dos produtores de ideias) e pelo trabalho na produção (indivíduos ativos). À proporção que vai se aprofundando a divisão, também vão-se aflorando as contradições entre as relações sociais existentes e as forças de produção, mostrando o modo como se apropriam e se controlam os elementos que integram uma dada sociedade. Ou seja, as relações entre as forças de produção, o estado social e a consciência entram em contradição numa dada divisão social do trabalho, demonstrando que a fruição e o trabalho, a produção e o consumo são determinados a indivíduos diferentes. As contradições são evidenciadas na divisão do trabalho na família, entre as diversas famílias, na distribuição quantitativa e qualitativa do trabalho e dos produtos. Cada indivíduo passa a ter um campo de atividade determinado, independente da sua vontade, e nele permanece. A força de produção, que nasce da cooperação de vários indivíduos, imposta pela divisão do trabalho, é uma forma estranhada aos próprios indivíduos, "situada fora deles, sobre a qual não sabem de onde veio nem para onde vai, uma potência, portanto, que não podem mais controlar (...), independente do querer e do agir dos homens e que até mesmo dirige esse querer e esse agir" (p.38).

No decorrer da história da humanidade, o trabalho assume diferentes formas e concepções, à proporção que as forças produtivas evoluem em consequência do aperfeiçoamento da divisão social do trabalho. Na evolução do processo histórico do capitalismo, a divisão do trabalho sofreu profundas transformações. Desenvolveu-se uma relação entre os indivíduos e a natureza, passada de geração em geração, mas modificada por gerações seguidas, somando uma massa de forças produtivas, capitais e formas sociais de intercâmbio, designando as condições de vida encontradas pelas diferentes gerações.

A primeira grande divisão social do trabalho foi aquela que separou o campo da cidade e criou a subordinação do homem do campo ao homem da cidade. Isso fez com que o processo de divisão do trabalho fosse se intensificando na moderna sociedade capitalista, em todos os âmbitos da atividade humana.

Na divisão do trabalho, está a origem da sociedade fragmentada em classes: a classe dos proprietários dos meios de produção e a classe explorada (proletária).

As classes sociais são demarcadas, conforme Poulantzas (1978), como um grupo de agentes sociais inseridos no processo de produção e com diferentes lugares na esfera econômica, política e ideológica da sociedade capitalista. A definição dos lugares ocupados pelos agentes sociais está no conjunto das práticas sociais, ou seja, na divisão social do trabalho, e eles correspondem a lugares de dominação, subordinação e resistência.

Que lugar os docentes ocupam na divisão social do trabalho? A resposta a esta questão está na análise acerca da divisão do trabalho. 
Numa sociedade dividida em classes, as relações sociais de produção são compostas pelas relações entre os agentes da produção, o objeto e os meios de trabalho; pelas relações entre os homens (as relações entre as classes), determinadas pela relação do não-trabalhador com o objeto e os meios de trabalho; e pela relação entre o trabalhador, o objeto e os meios de trabalho. Essas relações envolvem a propriedade econômica (proprietários), o controle econômico dos meios de produção e o domínio do processo de trabalho (trabalhadores). Quem detém o controle dos meios de produção explora aqueles que dominam o processo de trabalho sob variadas formas de sobretrabalho. A classe explorada (classe trabalhadora, operária, proletariada) é desprovida dos meios de produção, só possui sua força de trabalho, que é vendida no mercado, em forma de uma mercadoria, como qualquer outra. É a classe que desempenha o trabalho produtivo, essencialmente a produção de bens materiais. $O$ processo de produção na sociedade capitalista significa ao mesmo tempo, e num mesmo movimento, divisão de classes, exploração e luta de classes. (POULANTZAS, 1978).

A explicação dada por Poulantzas (1978) para classes sociais pode ser compreendida como uma definição "estreita" segundo Hunt (1977), pelo fato de definir a classe operária como constituída por trabalhadores produtivos. A definição dominante atribuída ao operário da sociedade industrial como produtor de bens materiais, como trabalhador produtivo, tem outra interpretação. A concepção de operário como aquele que exerce puramente o trabalho braçal se torna obsoleta com os avanços da divisão do trabalho, da mecanização e das atividades chamadas "infraprodutivas", que podem ser consideradas como atividades mais próximas da concepção e da reflexão; "o trabalho operário deixa de ser o paradigma da produção das 'obras"' (CASTEL, 1998, p. 458) e acha-se em qualquer relação de produção capitalista.

Hunt (1977, p. 112-116) explica que a noção de classe deve ser entendida segundo o conceito de relações sociais de produção. As classes são definidas como agregados sociais que ocupam posições comuns nas relações sociais de produção, as quais podem ser observadas na distinção entre as relações técnicas de produção e as relações de classe de produção. As primeiras correspondem às relações entre agentes de produção, constituídas pela ação direta das forças produtivas quando impõem formas de cooperação e de interação no trabalho (formas de gestão e organização do trabalho). Vale ressaltar que não são simples conjunto de vinculações entre produtores e agentes, mas relações entre o trabalho e o capital. As segundas correspondem às relações sociais de produção, conjunto de relações entre homens e mulheres, que resultam do mesmo processo de produção e são generalizadas na sociedade na relação entre o capital e o trabalho, independente da localização dos indivíduos no processo de produção. São estas relações que constituem as ligações entre a classe capitalista e a classe operária, fundamentais no capitalismo.

As classes se originam do conjunto de atividades que constituem as suas práticas, criando uma relação antagônica com outras classes, por um lado e, por outro, transportando para as relações mais próximas das práticas que determinam a identificação de classe de qualquer categoria da população. As práticas políticas e ideológicas estabelecem relações entre os membros de uma classe e demonstram o que une ou o que separa os seus membros (HUNT, 1977).

Os docentes, por sua vez, são destituídos dos meios de produção fora da atividade, possuem apenas a força de trabalho para ser vendida no mercado, têm o processo de trabalho normatizado pelo Estado e participam de associações e sindicatos semelhantes ao conjunto dos trabalhadores.

Numa definição "extensa" de classe operária, podemos incluir todas aquelas pessoas que vendem a sua força de trabalho como mercadoria em troca de um salário 
(trabalhadores estáveis e precários), abrangendo todos os trabalhadores que são remunerados, uma vez que podemos encontrar sempre dentro desse agregado divisões e subdivisões tanto materiais como ideológicas (GARDINER, 1977). A classe operária, nesse sentido, pode ser compreendida como um extrato que, ao longo dos anos, vem crescendo e assumindo uma estratificação mais complexa. O desenvolvimento das atividades no setor de serviços, por exemplo, origina o aumento de assalariados no comércio, nos bancos, na educação, etc. Surgem, desta visão mais alargada de classe operária moderna, interpretações acerca da sua evolução política no século $\mathrm{XX}$, aliadas às transformações que ocorreram no mundo do trabalho e ao lugar que os trabalhadores ocupam na condição de assalariados. Originam-se, daí, concepções quanto à formação de uma "nova classe operária", constituída pelo desenvolvimento das diferentes formas que a divisão do trabalho adota ${ }^{1}$.

A "nova classe operária" é formada pela expansão de categorias intermediárias, pela inserção de novos agentes e desempenha várias funções no processo de produção, como técnicos, engenheiros, operários de indústrias, que exercem mais o papel de mentores do que de executores e trabalhadores no setor de serviços. Esse grupo, ao lado de outros trabalhadores assalariados, vem sendo destituído do poder de decisão e do essencial dos benefícios de seu trabalho, em razão das diversas formas que a organização do trabalho assumiu no mundo capitalista, ou seja, está sendo proletarizado. Assim, como explica Castel (1998, p. 459), no que diz respeito ao antagonismo de classe - burguesia e proletariado - eles ocupam "uma posição análoga àquela do antigo proletariado e são, de agora em diante, os herdeiros privilegiados para retornar o empreendimento de transformação revolucionária da classe operária tradicional". Outros argumentos, segundo o autor, mostram que não há "uma nova classe operária"; há uma classe operária tradicional, que busca o apoio do grupo de assalariados (agentes intermediários), que se proletariza, e é definida por Braverman como "camadas médias", para o embate nos movimentos sociais. Nessa mesma linha de raciocínio, sucede o entendimento, oposto ao anterior, de que os agentes intermediários não estão sendo proletarizados, o que ocorre é o aburguesamento da classe operária, sustentando a ideia de que há uma elevação geral do nível de vida da classe operária, o que atenua os conflitos sociais.

Observamos que há uma dificuldade em situar de modo mais claro as divisões e subdivisões em que se reparte o conjunto da sociedade. A sociedade capitalista é formada por uma estrutura de classes sociais complexas, em que convivem as classes sociais das relações pré-capitalistas (os pequenos proprietários de fazenda, comércio, serviços liberais e artesãos), ao lado da burguesia e do proletariado fabril, e, entre esses grupos, se faz presente uma heterogênea composição social das classes médias.

As discussões em torno dos conceitos que classificam uma massa de trabalhadores como pertencente a um extrato das classes médias são alvos de críticas, em razão de promoverem a anulação da classe operária, escamoteando, assim, os conflitos sociais (CASTEL, 1998). Em síntese, há um amplo debate entre posições que adotam o ponto de vista da presença de uma acentuada proletarização de setores da classe média (camada média, definida por Braverman) e posições que defendem a emergência de uma "nova classe operária", em razão da expansão de agentes intermediários, que estão sendo proletarizados. Nesse debate, podemos situar a posição social dos professores do ensino fundamental e médio como pertencentes à classe média (PESSANHA, 1994) proletarizada, ou situá-los na "nova classe operária" ou "nova classe média".

Se não conseguirmos encontrar uma definição exata para situar a posição social do professor, compreendemos que é possível a sua condição de categoria proletarizada. 
Marx, conforme Bootomore (2001, p. 65), se referia ao termo "classe média" como "pequena burguesia", classificando-a como camada social que está entre a burguesia e a classe operária pela tendência crescente desse grupo, em função do desenvolvimento do capitalismo, ter uma face política conservadora e reformista. Marx e Engels não se preocuparam em estabelecer diferenças entre a "velha classe média", formada por pequenos produtores, artesãos, profissionais independentes, e a "nova classe média", composta por trabalhadores em escritórios, supervisores, técnicos, funcionários do governo, incluindo também nesse grupo os professores que vivenciam situações semelhantes ao proletariado, inclusive nos conflitos no movimento sindical.

As bandeiras de luta do proletariado tradicional são também lemas agregados às novas categorias profissionais das classes médias, em resistência ao processo de proletarização a que estão sujeitas na produção capitalista, que passaram a se organizar em sindicatos, nas décadas de 1960 e 1970, contra a ditadura militar e o desenvolvimento autoritário das relações capitalistas. Os professores públicos estaduais começaram a participar das manifestações maciças nesse período, com mobilizações e grande capacidade de organização, constituindo "numa das mais importantes categorias do universo social das classes médias (FERREIRA Jr e BITTAR, 2006, p. 59-60).

\section{Sobre as teses da proletarização do professor}

As linhas de análise da tese da proletarização do trabalho do professor, especialmente do ensino fundamental e médio, fazem referência à desqualificação da prática pedagógica, ao modo como está organizado o trabalho nas escolas, como também, às condições socioeconômicas a que foram submetidos os professores, que, em vista disso, passaram a se organizar politicamente. Os debates situam-se em torno de interpretações que, de uma forma, explicam o trabalho docente como caracteristicamente capitalista, ou como não capitalista e, de outra, descartam a polarização e buscam esclarecer o trabalho docente como síntese de relações sociais, considerando os professores como sujeitos participativos que se aliam a outros trabalhadores como prática de resistência, a exemplo da luta contra o regime militar nas manifestações sindicais da categoria.

Os debates sobre a figura do professor fazem parte de estudos que relembram a função docente, ocupada ora por pessoas, ora consideradas como mestre-de-ofício (ARROYO, 1985 apud HYPOLITO, 1997) ora como professor-artesão (SÁ, 1986), que atuavam muitas vezes como autodidatas e eram o centro do processo educativo, sem possuir, como lembra Hypolito, as características de um profissional com ocupação regulamentada legalmente pelo Estado. A partir dos anos 1920, crescem as contratações de professores pelo Estado, e os mestres passam a ter as suas funções regimentadas e a tornarse assalariados do governo.

$\mathrm{Na}$ condição de assalariados, os professores são submetidos a um processo de desvalorização profissional, à medida que a profissão vem sendo desvalorizada pelos baixos salários e pela perda de prestígio e status. Em face disso, no final dos anos 1970, nascem os sindicatos com o objetivo de defender as condições sociais e de trabalho dos professores nos mesmos moldes que as entidades sindicais de trabalhadores (HYPOLITO, 1997; FERREIRA Jr e BITTAR, 2006). Nesse contexto, muitos pesquisadores da área de educação focaram os seus estudos em torno de questões que procuravam analisar o trabalho do professor, segundo diferentes ângulos, surgindo, daí, várias publicações.

A pesquisa desenvolvida por Tumolo e Fontana (2008) realizou um levantamento da produção acadêmica acerca do trabalho docente. Inventariaram trinta e nove publicações: três teses, quinze dissertações, onze artigos, dez livros e elaboraram uma 
síntese das principais análises. Segundo esses autores, os estudos sobre a proletarização estão relacionados às discussões a respeito da identificação da proletarização do docente como um processo que se opõe à profissionalização, com destaque para as discussões sobre a feminização do magistério; a (re)organização escolar e a atividade docente; a organização de classe e o docente como trabalhador produtivo. Constataram, após as análises das pesquisas, que

(...) a proletarização é percebida como um processo inerente à desqualificação e precarização do trabalho docente, em decorrência das mudanças ocorridas na sociedade capitalista e, como consequência, no processo de trabalho do professor. Ao contrário da proletarização, a profissionalização é afirmada como um movimento que promove a categoria do magistério à consolidação desses trabalhadores como profissionais. Além disso, nota-se que as explicações que os autores ofereceram sobre trabalho produtivo e proletarização docente são bastante díspares e, em alguns casos, acentuadamente divergentes. Isso se deve não ao foco que deram ao tema eleito, mas, possivelmente, à escolha de referenciais teóricos também distintos que foram utilizados para analisar o trabalho docente. (p.3)

Entre as principais discussões sobre o trabalho docente, elencamos algumas contribuições que mais se destacaram para ilustrar o debate.

Em Apple e Teitelbaun (1991, p.67), o destaque é dado à presença de um processo de desqualificação ${ }^{2}$ do trabalho docente. As mudanças sucedidas no currículo e no processo de controle do trabalho, no ensino, motivaram importantes implicações na qualificação dos professores. Apesar de a atividade da educação ser diferente daquela presente na linha de montagem ou mesmo no setor de serviços, ela sofre as mesmas pressões. Segundo os autores, muitos professores deixaram de planejar e controlar uma parte de seu próprio trabalho, porque o planejamento, a escolha dos métodos de ensino e a elaboração de textos e testes estão sendo delegados para as secretarias de educação, direção de escolas e assembleias estaduais. "Em vez de professores profissionais que se importam muito com o que fazem e por que o fazem, podemos ter executores alienados de planos alheios".

Corroborando com a opinião de Apple e Teitelbaun, como defensores da tese da desqualificação do trabalho docente, Pucci et al. (1991) compreendem o trabalho do professor de ensino fundamental e médio em duas vertentes complementares:

Por um lado, os professores aproximam-se de outros trabalhadores em termos de relações de trabalho: a longa jornada de trabalho racionalizado faz com que não consigam desligar-se da sua ocupação; o controle do seu corpo é definido pela organização do trabalho, pelos movimentos de ir e vir nas salas em diferentes turmas e turnos; após as aulas, há planejamento e acompanhamento dos procedimentos desenvolvidos na escola; a sua valorização é compensada mediante mais-trabalho, isto é, a rotina da atividade na sala de aula; e, como não têm tempo para maiores aprofundamentos, como pensar sobre o sistema educacional, conferem estas atribuições a outras pessoas (direção da escola e governo).

Por outro lado, os professores assemelham-se, no processo de organização de luta, à classe operária, fabril, quando se organizam em sindicatos e associações de classe, constituindo trabalhadores coletivos. Presenciam-se, em todos os estados brasileiros, movimentos de professores em luta por melhores condições salariais e de trabalho, evidenciando que essa profissão tornou-se uma atividade de massa. Do ponto de vista de 
Fernandes (1987, p.31), num passado recente, seria considerada uma afronta para um professor ser chamado "assalariado", mas, atualmente a situação é inversa, “... se impõem certas normas na revalorização econômica da categoria profissional e na conquista de maior liberdade em outro espaço cultural".

Hypolito (1997) utiliza três categorias para interpretar o trabalho docente: natureza, posição de classe social e relações de gênero. Nas conclusões das suas análises, ele reconhece que o processo de trabalho docente é subordinado a uma lógica capitalista de racionalização e organização reguladas pelas políticas do Estado; a proletarização é proveniente do processo de assalariamento e precarização profissional a que está sujeito o conjunto dos trabalhadores; e, por último, tendo por base as análises de gênero, observa que a categoria, principalmente a dos professores do ensino fundamental, sofreu um processo de feminização e, por isso, é desvalorizada.

Enguita (1991, p.41) questiona a tese da proletarização, argumentando que, na polêmica em torno do estatuto social e ocupacional dos docentes, a questão salarial é apenas o ponto aparente. Ele assinala a posição de que "nem a sociedade em que (os professores) estão inseridos consegue pôr-se de acordo com a sua imagem social e menos ainda sobre suas consequências práticas em termos de delimitação de campos de competência, organização da carreira docente, etc. Em sua opinião, a categoria dos professores situa-se em uma posição intermediária entre a "profissionalização ${ }^{3}$ e a

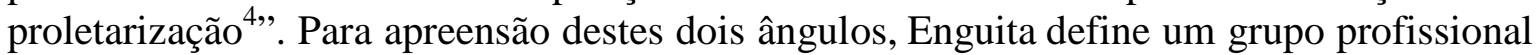
como uma categoria que se caracteriza pelo exercício de conhecimentos técnicos e intelectuais, sem vínculo hierárquico, marcada por uma posição de privilégio monopolista, como médicos e advogados, embora considere que alguns desses profissionais trabalhem como assalariados para organizações públicas e privadas. Mas, ainda se trata de um grupo com grande força corporativa e privilégios em termo de salários e prestígio:

O que faz com que um grupo ocupacional vá parar nas fileiras privilegiadas dos profissionais ou nas desfavorecidas da classe operária não é a natureza dos bens ou serviços que oferece, nem a maior ou menor complexidade do processo global de sua produção, mas a possibilidade de decompor este último através da divisão do trabalho e da mecanização... (ENGUITA, 1991, p.42).

Segundo essa perspectiva, depreende-se que os grupos ocupacionais, geralmente, giram em torno de características de profissionalização e proletarização. Podem-se definir com mais clareza as condições de trabalho dos docentes, comparando-as às distinções profissionais de médicos e advogados (ENGUITA, 1991).

Competência. É necessário que o profissional seja dono de um saber específico, outorgado para tal, reconhecido e aceito pela sociedade. Um saber controlado pela classe, mistificado como "sagrado", ou seja, não pode ser avaliado pelos profanos, e, sim, julgado pelos membros da mesma classe. Os licenciados possuem competência oficialmente reconhecida em seu campo, mas o seu saber não tem nada de "sagrado", isto é, qualquer pessoa alheia à profissão sente-se no direito de opinar sobre a profissão, julgá-la, exercê-la e ser aceito naturalmente pela sociedade.

Vocação. Os motivos que levam um indivíduo a escolher uma profissão são mais no sentido material e simbólico do que vocacional. A troca dos serviços prestados é em forma de honorários, às vezes dentro da conveniência do profissional. No magistério, a ideia de vocação sempre esteve presente - na postura ideológica do profissional abnegado, que trabalha por vocação, como um sacerdote, e na imagem do professor associada a um ser especialmente repressor do ponto de vista de tabus. Hoje, com a expansão do 
capitalismo e dos bens de consumo, "a imagem do professor graduado num curso universitário que se dedica ao ensino se move entre alguém que renunciou à ambição econômica em favor de uma vocação social e de quem não soube nem conseguiu encontrar algo melhor" (ENGUITA, 1991, p.45).

Licença. $\mathrm{O}$ conjunto dos profissionais, geralmente, tem o seu espaço demarcado pelos conselhos e leis autorizados pelo Estado. No magistério, o campo é definido em parte. Há liberdade para o exercício do ensino por outros profissionais, por estagiários.

Independência. A autonomia dos profissionais liberais frente às organizações e aos clientes é reconhecida. Eles exercem controle sobre as ações no seu ambiente de trabalho mesmo quando são assalariados. A autonomia dos docentes é parcial, tanto frente às instituições em que trabalham como ao seu público. A maioria é assalariada.

Auto-regulação. Os conselhos, por meio do próprio código de ética, normalizam a profissão e julgam os casos improcedentes ou não. A regulação da profissão é geralmente baseada nas regras definidas pelos pares. No campo do magistério, os estatutos são definidos e controlados pelas secretárias de educação. Os docentes contam apenas com o sindicato e as associações para lutar por seus direitos.

Vale ressaltar que existe uma flexibilização das funções no mercado de ocupações e que nem todas as profissões conseguem demarcar um monopólio definido.

Outras linhas de análise fazem críticas à tese da proletarização. Em estudo histórico recente, Ozga e Lawn (1991) levantam alguns pontos críticos, principalmente nos estudos inspirados no trabalho de Braverman ${ }^{5}$, cuja análise está centrada na tese da desqualificação e do controle da classe trabalhadora pela gerência da empresa capitalista. A crítica principal à tese fundamenta-se no fato de que o trabalho de ensinar é refratário à rotina, a tarefas fragmentadas. Reconhecem que as mudanças no processo e na organização do trabalho afetam a natureza do ensino, mas os professores não podem se igualar aos trabalhadores fabris. Eles criticaram a tese da proletarização ${ }^{6}$ do trabalho docente, com base em pesquisas etnográficas. As contestações feitas por Ozga e Lawn (1991) apontam para o fato de que o processo não é tão generalizado do modo como Braverman afirmava. A base dos argumentos desses autores mostra que os estudos sobre o trabalho docente devem levar em conta as mudanças ocorridas no processo de trabalho na escola, e não as mudanças centradas nos processos de administração na indústria ou no escritório; ou seja, entender como os professores vivenciam o ensinar, observando as ações coletivas, as culturas, as estratégias e as lutas dos grupos. As atitudes de controle propostas pela administração nas escolas encontram barreiras nos professores como uma estratégia de barganha e negociação das ações coletivas, como também as experiências de vida e de ensino mostram que as qualificações dos professores são socialmente construídas. Segundo Ozga e Lawn (op.cit., 156), as ações dos professores são coletivamente produzidas e barganhadas nas relações de trabalho no "chão" da escola.

Na mesma direção, Jáen (1991, p.76) questiona a tese da proletarização baseada nos estudos desenvolvidos por Braverman. A autora explica que a história das transformações racionalizadoras do trabalho é atravessada por conflitos e enfrentamentos entre trabalhadores e empregados. No centro do trabalho educacional, os conflitos estão presentes: "os docentes têm desenvolvido formas diversas de respostas entre as quais se destacam certas vertentes da estratégia 'profissionalista', assim como fórmulas que vão desde o compromisso militante consciente, até as ações individuais (muitas vezes inconscientes), dirigidas contra aspectos parciais do processo "racionalizador"'. Interpreta a proletarização como a "degradação das condições de trabalho no ensino e a criação de resistências pelo professorado frente ao Estado, enquanto agente 'racionalizador', como 
processos que equiparam sua situação a dos trabalhadores industriais e que os assimilam (ou pode chegar a assimilá-los) à classe operária”.

As análises elaboradas por Deber, citadas por Jáen, (1991, p.77), questionam a tese da proletarização. Deber argumenta que, no âmbito da racionalização do trabalho, existem distintas formas de proletarização da força de trabalho. O controle dos sujeitos pode modificar-se "não só em função dos modos em que é exercido (tal como se pode admitir entre os teóricos da proletarização)", mas, também, de forma dissimulada pela administração. Para tanto, especifica dois tipos de proletarização que sempre se fizeram presentes no controle da produção: a proletarização "técnica" e a "ideológica." Ambas são de fundamental importância para compreensão dos profissionais, especialmente a "proletarização ideológica". O primeiro tipo foi amplamente discutido por Braverman. A proletarização ideológica representa, para Deber, uma análise diferente sobre o controle nas instituições. Ou seja, os trabalhadores têm apresentado diferentes respostas à perda de controle do seu trabalho, portanto reagem de forma distinta ao domínio ideológico. A "acomodação" dos profissionais ao controle é entendida como forma estratégica de "defesa". Um grupo submete-se a "dessensibilização ideológica (...) negação ou separação do trabalhador do contexto ideológico de seu emprego" (DEBER, citado por JÁEN, 1991, p.79). O que interessa é o desenvolvimento "científico" e "técnico" do trabalho. Outro grupo aceita a cooptação ideológica e é identificado segundo os propósitos morais definidos por outros. Acredita nos objetivos definidos pela empresa como sendo seus.

Esses dois elementos refletem a adaptação dos sujeitos ao controle das instituições e representam uma tentativa de compreender as diferenças de comportamento dos trabalhadores da indústria e de outros profissionais. Para Derber, com base no entendimento da "proletarização ideológica", começam a ser esclarecidas as diferenças entre os trabalhadores industriais e os docentes. Estes passam periodicamente por um processo de requalificação e estão mais vulneráveis ao processo de transmissão ideológica e cultural propagada pelos administradores do Estado.

Estas análises destacadas, de modo geral, explicam a proletarização tendo em vista o processo de assalariamento, a racionalização e a precarização do trabalho docente, buscando homogeneizá-lo segundo as formas de organização e gestão do trabalho comum ao conjunto dos trabalhadores. As críticas a essas análises são feitas por pesquisadores que consideraram fundamental observar primeiro as mudanças ocorridas nas escolas, levar em conta a diversidade do campo educacional e observar as formas como o trabalho é organizado a partir de pesquisas empíricas, antes de elaborar inferências a respeito do trabalho docente.

Lüdke e Boing (2007) lembram que o tema "trabalho docente" é polêmico e, ao ser estudado, devem-se levar em conta as transformações sociais e econômicas que estão ocorrendo no mundo contemporâneo. As atuais estratégias de gestão e organização do trabalho na escola buscam submeter os professores a um tipo de gestão baseado na lógica do mercado.

\section{PALAVRAS FINAIS}

As discussões apresentadas neste texto buscam compreender a categoria proletarização como um conceito pertinente à ideia de proletariado, de classe proletária, operária. Considera-se proletária a classe que é explorada no modo de produção capitalista, tanto nas relações técnicas de produção como nas relações de classe de produção. Nas diversas formas que a organização do trabalho assumiu desde a manufatura, formas de cooperação e de interação no trabalho sempre estiveram presentes, demarcando um caráter 
de subordinação e de resistência do homem ao trabalho, a exemplo das práticas que dividiram as formas artesanais de produção, evidenciadas na evolução do processo histórico de expropriação gradativa do trabalhador dos seus instrumentos de trabalho. As razões que levam o trabalho docente a ser rotulado de proletarizado podem ser compreendidas à luz dessas explicações. Ainda que consideremos o quanto o trabalho docente não é desenvolvido nas mesmas condições dos trabalhadores das indústrias, ele está submetido aos mesmos processos estruturais da maioria dos trabalhadores assalariados.

À luz das considerações aqui desenvolvidas, podemos concluir que mudanças ocorridas no mundo trabalho causam impactos no trabalho docente. As transformações que aconteceram em decorrência do processo de reestruturação produtiva, implementado no último quartel do século XX, e a investida neoliberal no campo educacional introduziram conceitos na área educacional, como qualidade, eficiência, equidade, ditados pelas políticas de ajustes do Banco Mundial, constituindo em dispositivos reguladores do sistema educativo e, consequentemente, gestando o modo como o trabalho docente deve ser organizado na escola. O projeto de educação proposto para a América Latina, do governo de FHC, defendeu, como uma das metas a ser alcançadas, o rebaixamento dos salários, o controle do trabalho dos professores, justificado pelo fato de esses profissionais serem responsáveis pela formação de futuros trabalhadores (formação de uma classe trabalhadora assalariada). Isso de certa forma nos dá uma ideia da racionalização do trabalho, quando observamos o controle exercido pelo Estado nos planos políticos e ideológicos. Em termos da relação funcional do trabalho com o capital, tendo em vista as necessidades de acumulação e legitimação do capitalismo, os professores são responsáveis pela reprodução da força de trabalho.

No que diz respeito ao lugar ocupado pelos professores na divisão técnica do trabalho, nas tarefas que realizam em suas atividades, é evidente o fato que o trabalho docente vem a cada dia expressando menos autonomia, maior divisão, intensificação e fragmentação.

Quando utilizamos o conjunto dessas interpretações para esclarecer o processo de proletarização do trabalho docente segundo a posição social, nos inserimos no debate sobre a expansão de categorias intermediárias, "camadas médias". Os professores do ensino fundamental e médio são classificados como pertencentes a esse grupo. Entretanto, o avanço das inovações tecnológicas e organizacionais vem transformando amplamente as forças produtivas e, com isso, aumentando o quantitativo de trabalhadores integrante de "uma nova classe operária" (ou trabalhadora). Assim, incluímos os professores nesta classe, que, a cada dia, vem sendo multifacetada em atividades precárias e flexibilizadas.

\section{REFERÊNCIAS}

ANTUNES, R. Século XXI: nova era da precarização estrutural do trabalho? In ; BRAGA,

R. Infoproletários: degradação real do trabalho virtual. São Paulo: Boitempo, 2009.

APPLE, Michael; KENNETH, Teitelbaun. Está o professorado perdendo o controle de suas qualificações e do currículo? Teoria \& Educação. Porto Alegre, n.4, p.62-73, 1991.

BRAVERMAN, Harry. Trabalho e capital monopolista: a degradação do trabalho no século XX. Rio de Janeiro: Jorge Zahar, 1980. 
BOTTOMORE, T. Dicionário do pensamento marxista. Rio de Janeiro: Jorge Zahar, 2001. p.64-67.

CASTEL, R. As metamorfoses da Questão Social: uma crônica do salário. Rio de Janeiro: Vozes, 1998. (Col. Zero à Esquerda)

COSTA, M.C.V. Trabalho docente e profissionalismo: uma análise sobre gênero, classe e profissionalismo no trabalho de professoras e professores de classes populares. Porto Alegre: Sulina, 1995.

ENGUITA, Mariano F. A ambiguidade da docência: entre o profissionalismo e a proletarização. Teoria \& Educação. Porto Alegre, n.4, p.41-61, 1991.

FERNANDES, Florestan. A formação política e o trabalho do professor. In: Catani, Denice Bárbara et al. (org). Universidade, escola e formação de professores, $2^{\mathrm{a}}$ ed., São Paulo: Brasiliense, 1987. p. 13-37.

FERREIRA JR, A. e BITTAR, M. Proletarização e sindicalismo de professores na ditadura militar (1964 - 1985). São Paulo: Terras do Sonhar: Pulsar, 2006.

FERREIRA, M. O. V. Somos todos trabalhadores em Educação? Reflexões sobre identidades docentes desde a perspectiva de sindicalistas. Revista Educação e Pesquisa, v.32, n.2, S. P. maio/ago.2006. p. 1-12.

GARDINER, J. As mulheres no processo de trabalho e na luta de classes. In: estrutura das classes. Tradução José Calisto. Lisboa: Edições 70, 1977. p.177-187.

(org) Classes e

HUNT, A. Teoria e Política na identificação da classe operária. In: das classes. Tradução José Calisto. Lisboa: Edições 70, 1977. p.93-128.

(org) Classes e estrutura

HYPÓLITO, A.L. Trabalho docente: classe social e relações de gênero. Campinas: Papirus, 1997.

JÁEN, Marta Jiménez. Os docentes e a racionalização do trabalho em educação: Elementos para uma crítica da teoria da proletarização dos docentes. Teoria \& Educação, Porto Alegre, n.4, p.7490, 1991.

LÜDKE, M.; BOING L. A. O trabalho docente nas páginas de Educação \& Sociedade em seus (quase) 100 números. Revista Educação e Sociedade, v.28, n 100, Campinas, SP, out. 2007.p. 1-10.

MARX, K; ENGELS, F. A ideologia alemã. Tradução de R. Enderle, N. Schneider e L.C. Martorano. São Paulo: Boitempo, 2007.

OZGA, Jenny e LAWN, Martin. Processo de trabalho do ensino. Teoria \& Educação, Porto Alegre, RS, n.4, p.140-157, 1991.

PESSANHA, Eurize Caldas. Ascensão e queda do professor. São Paulo: Cortez, 1994.

POULANTZAS, N. As classes sociais e a sua reprodução ampliada. In: As classes sociais no capitalismo de hoje. Rio de Janeiro: Zahar, 1978.p. 13-38.

PUCCI, Bruno at al. O processo de proletarização dos trabalhadores em educação. Teoria \& Educação, Porto Alegre: n. 4, p.91-108, 1991.

SÁ, N. P. O aprofundamento das relações capitalistas no interior da escola. Cadernos de Pesquisa, n 57, p.20-29, SP, maí, 1986.

TUMOLO, P. S.; FONTANA, K. B. Trabalho docente e capitalismo: um estudo crítico da produção acadêmica da década de 1990. Educação e Sociedade, .29 n.102 Campinas jan./abr. 2008, p. 1-11. Disponível em: http://www.scielo.br/scielo.php?script=sci_arttext\&pid=S0101$73302008000100009 \& \operatorname{lng}=\mathrm{pt} \& \mathrm{nrm}=\mathrm{iso}$ 


\footnotetext{
${ }^{1}$ Antunes (2009, p.238) esclarece que pode ser considerada classe trabalhadora: os trabalhadores "produtivos que participam diretamente do processo de criação de mais-valia e da valorização do capital que hoje transcende em muito as atividades industriais, dada a ampliação dos setores produtivos nos serviços -, quanto os trabalhadores improdutivos - que não criam diretamente mais-valia, uma vez que são utilizados como serviço, seja para uso público, como os serviços públicos, seja para uso capitalista".

${ }^{2} \mathrm{O}$ termo desqualificação está relacionado à separação entre concepção e execução com outra característica, que é a perda do controle dos trabalhadores sobre o seu próprio trabalho para a administração da escola.

3 A expressão profissionalização, para Enguita, (1991, p.41) não é entendida como sinônimo de "qualificação, conhecimento, capacidade, formação e outros traços associados, mas como expressão de uma posição social e ocupacional, da inserção em um tipo determinado de relações sociais de produção e de processo de trabalho" (ENGUITA, 1991, p.41).

${ }^{4} \mathrm{~A}$ expressão proletarização sugere um sentido oposto à profissionalização, mas deve ser entendido como "livre das conotações superficiais que associam unilateralmente ao trabalho fabril" (p.41).

${ }^{5}$ Os autores referem-se a Braverman na medida em que este centra a sua análise na desqualificação dos trabalhadores e controle do processo de trabalho pela administração, implicando a proletarização entre professores como uma forma de "recuperá-los" para a classe operária.

${ }^{6} \mathrm{O}$ termo proletarização é definido no texto como um processo que resulta da perda do trabalhador da capacidade de planejar e executar ao mesmo tempo o seu próprio trabalho, ou seja, separação entre concepção e execução, e a divisão da execução em partes distintas e aumento de controles administrativos.
}

Artigo recebido em: 07/02/10

Aprovado para publicação em: 05/03/10 